\title{
PSYCHIATRY
}

\section{No confidence in wrong actions}

Neuron 96, 348-354 (2017)

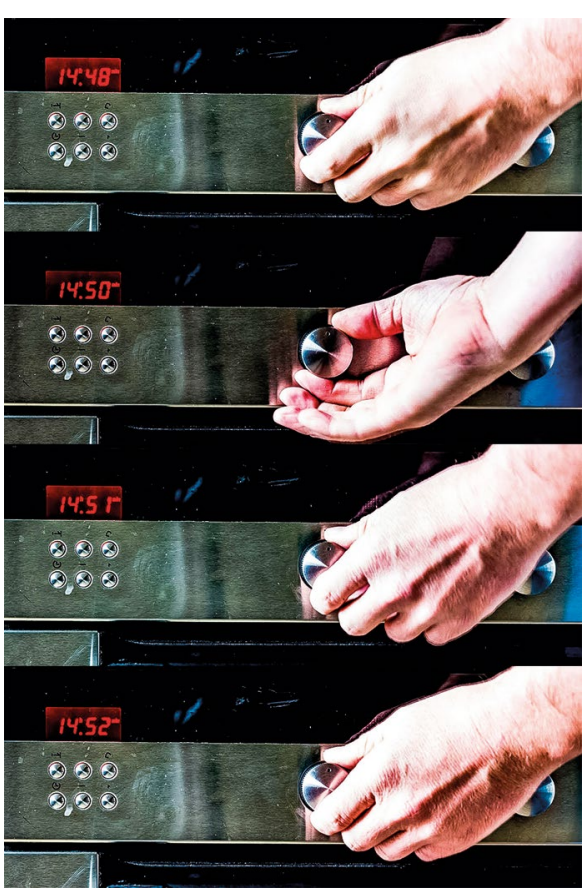

Credit: Phanie / Alamy Stock Photo

Obsessive-compulsive disorder (OCD) is often associated with the urge to perform ritualistic actions, such as checking or washing. Strikingly, OCD sufferers usually know that these actions are not necessary and that repetition fulfils no real purpose. This raises the question whether OCD involves a more general problem in choosing and evaluating actions.

Matilde Vaghi and Fabrice Luyckx, of Cambridge University, and colleagues show that OCD patients may suffer from a specific impairment in choosing the right action - despite their intact ability to evaluate success. The researchers used a computerized task in which patients and controls caught flying particles by placing a (virtual) bucket where they predicted these to land. Participants then indicated their confidence in their placement. Where particles landed always varied slightly, with occasional drastic changes in position. Compared with controls, OCD patients often adjusted actions too much in response to small errors, while their confidence in their placements showed that they had some insight that these large adjustments were unwarranted.

The researchers say that these findings raise new questions about the link between actions and confidence, and that it is important to understand whether OCD entails changes in brain function relating to evaluation and choice of action.

Anne-Marike Schiffer

Published online: 23 November 2017

https://doi.org/10.1038/s41562-017-0263-6 